\title{
Predictability of Al-Mn Alloy Exposure Time Based on Its As-Cast Weight and Corrosion Rate in Sea Water Environment
}

\author{
Chukwuka Nwoye $^{1 *}$, Simeon Neife ${ }^{2}$, Ebere Ameh ${ }^{3}$, Awo Nwobasi ${ }^{4}$, Ndubuisi Idenyi $^{5}$ \\ ${ }^{1}$ Department of Metallurgical and Materials Engineering, Nnamdi Azikiwe University, Awka, Nigeria \\ ${ }^{2}$ Department of Metallurgical and Materials Engineering, University of Nigeria, Nsukka, Nigeria \\ ${ }^{3}$ Department of Metallurgical and Materials Engineering, Enugu State University of Science \& Technology, Enugu, Nigeria \\ ${ }^{4}$ Department of Technology and Vocational Education, Ebonyi State University, Abakiliki, Nigeria \\ ${ }^{5}$ Department of Industrial Physics, Ebonyi State University, Abakaliki, Nigeria \\ Email: "chikeyn@yahoo.com
}

Received September 8, 2013; revised October 18, 2013; accepted October 30, 2013

Copyright (C) 2013 Chukwuka Nwoye et al. This is an open access article distributed under the Creative Commons Attribution License, which permits unrestricted use, distribution, and reproduction in any medium, provided the original work is properly cited.

\begin{abstract}
This paper presents the predictability of aluminium-manganese alloy exposure time based on its as-cast weight and corrosion rate in sea water environment. The validity of the derived model: $\alpha=26.67 \gamma+0.55 \beta-0.29$ is rooted on the core expression: $0.0375 \alpha=\gamma+0.0206 \beta-0.0109$ where both sides of the expression are correspondingly approximately equal. Statistical analysis of model-predicted and experimentally evaluated exposure time for each value of as-cast weight and alloy corrosion rate considered shows a standard error of $0.0017 \% \& 0.0044 \%$ and $0.0140 \% \& 0.0150 \%$ respectively. The depths of corrosion penetration (at increasing corrosion rate: $0.0104-0.0157 \mathrm{~mm} / \mathrm{yr}$ ) as predicted by derived model and obtained from experiment are $0.7208 \times 10^{-4} \& 1.0123 \times 10^{-4} \mathrm{~mm}$ and $2.5460 \times 10^{-4} \& 1.8240 \times 10^{-4}$ $\mathrm{mm}$ (at decreasing corrosion rate: $0.0157-0.0062 \mathrm{~mm} / \mathrm{yr}$ ) respectively. Deviational analysis indicates that the maximum deviation of the model-predicted alloy exposure time from the corresponding experimental value is less than $10 \%$.
\end{abstract}

Keywords: Prediction; Exposure Time; Al-Mn Alloys; Sea Water; Alloy As-Cast Weight; Corrosion Rate

\section{Introduction}

The service performance of metals (or alloy), irrespective of the exposure environment is largely affected by their physical and mechanical properties such as hardness, weldability, toughness, malleability, ductility, resistance to fatique etc. It is therefore vital to consider these and other basic properties of metals or alloys when proposing their application for fabrication and other engineering purposes.

Researchers [1] have suggested the need to know the specific corrosion rates of different metals and alloys in different application environment in order to know the materials that can withstand outdoor structural applications.

The stability of metals or alloys in an aggressive environment has been reported [2] to basically depend on the protective properties of organic or inorganic films as well

${ }^{*}$ Corresponding author. as on the layer of corrosion products. The scientists concluded that the ability of films to act as controlling barriers against different kinds of corrosion attack is dependent on film properties such as chemical composition, adhesion, conductivity, solubility, morphology and hygroscopicity. Several researchers $[1,3]$ reported that the highlighted characteristic of films in turn depends on environmental variables such as atmospheric conditions, type and amount of pollutants as well as wet-dry cycle, the chemical composition and metallurgical history of the metals or alloys and physicochemical properties of coating.

Malfunctioning of engineering structures and equipment due to corrosion has been reported [4] to stem from tragic carelessness in plumbing, equipment manufacture and installation, with possibility of explosion, fire and spread of toxic materials in living environment. This is accompanied by some costs such as replacement of corroded equipment, disturbance in processes due to equip- 
ment corrosion, shutdown of plants due to replacement of corroded equipment, impurity in processed products due to corrosion as well as waste of the products of those vessels which are attacked by corrosion. The report indicates that about 70 percent of losses can be prevented by observing related principles and instructions.

One of the main problems in oil and gas industries is corrosion of pipelines and other engineering structures. This has always resulted in huge economic setback due to large sum of money spent in trying to combat it. Based on the forgoing, there is a great need to develop engineering materials that are corrosion resistant to avoid abrupt failure of the engineering structures.

Recently, the corrosion characteristics of selected ferrous metal samples (plain and alloyed ductile iron, low carbon steel and austenitic stainless steel) in crude oil were investigated by using weight loss method [5]. Studies carried out during this work show that all the materials experience gain in weight within the first 10 days in the medium. This weight gain is attributed to the formation of hard and passive phases which acted as strong protective barriers to corrosion. It was also observed that the rate of corrosion decreased with increase in the number of days of exposure for all the coupons, this may be probably due to the deposition of corrosion products that tend to shield the corroding surface from further corrosion attack, thereby depressing the rate of corrosion. This result shows that despite of initial low corrosion resistance of plain ductile iron, it can still be considered, alongside other materials, for application in pipelines and storage facilities for crude oil.

Studies [6] on the corrosion behaviour of carbon steel under natural and stagnant seawater conditions have showed that the alloy is more corrosive in anaerobic stagnant sea-water conditions than that in aerobic conditions. The study also revealed that in both aerobic and anaerobic exposures, corrosion was more aggressive on horizontally oriented coupons compared to vertically oriented samples.

The corrosion behaviour of low carbon steel has also been investigated [7] in natural seawater and various synthetic seawaters. It was found that the steel corroded nearly four times faster in a $3.5 \% \mathrm{NaCl}$ solution than in natural seawater for an exposure time of 21 days. The corrosion rate after immersion in synthetic seawaters was found to be similar to the corrosion rate after immersion in natural seawater. Calcium carbonate (aragonite) deposits were found on the surface of the steel after immersion in natural seawater and the synthetic seawaters. Some magnesium-containing deposits were also found after immersion in the natural seawater. These deposits act as a barrier against oxygen diffusion and thereby lower the corrosion rate. The morphology of the calcium carbonate deposits that formed during immersion in the natural seawater was found to be different from those formed during immersion in the solution.

It has been shown [8] that $\mathrm{MnAl}_{6}$ formed from $\mathrm{Al}$ and Mn has almost the same electrode potential as aluminium and this compound is capable of dissolving iron which reduces the detrimental effect of Mn. Commercial Al-Mn alloys contains up to $1.25 \%$ manganese although the maximum solid solubility of this element in aluminium is as high as $1.82 \%$. This limitation was imposed because the presence of iron as impurity reduces the solubility and there is a danger that large primary particles of $\mathrm{MnAl}_{6}$ will form with a disastrous effect on local ductility.

Polmear [8] reported that Al-Mn alloys belong to the $3 \mathrm{xxx}$ series of alloys which are used for the manufacture of roofing sheets. These sheets are subject to corrosion because of the presence of moisture and oxygen in the atmosphere. The corrosion of this alloy is due to the strong affinity aluminium has for oxygen which results to its oxidation and subsequent formation of oxide film. Ekuma et al. [9] reported that with time, this film becomes passive to further oxidation and stable in aqueous media when the $\mathrm{pH}$ is between 4.0 and 8.5. It is important to state that the passive films can break and fall off, hence exposing the surface of the alloy to further corrosion.

Studies [4] on corrosion management indicate that it offers preventive strategies in two technical and nontechnical domains. Technical domains as preventive strategies are highly important. These includes: 1) Upgrading planning methods and using advanced planning ones to better corrosion management and so prevent avoidable corrosion costs. In this vein, planning methods must change and the best corrosion technologies must be available for planners. 2) Improving corrosion technologies via research and development. Corrosion can be controlled in most industries by using scientific methods and new technological achievements.

Non-technical domain as preventive strategies includes: 1) Enhancing the employees' awareness about the high costs of corrosion and saving costs result in correct application of existing technologies and corrosion costs. Thus a lot of corrosion problems are due to lack of awareness about corrosion management and accountability of people in exchanging operations, inspection and maintenance of management system. 2) Changing guidelines, protocols, standards and management methods to reduce corrosion costs by correct corrosion management, resulting in effective control of corrosion and safe operation and increase in shelf life of equipment. 3) Amending and generalization of employees' instruction to introduce and identify corrosion control. 4) Changing and amending wrong belief about not being able to do anything about corrosion and making new decisions in pre- 
venting this phenomenon.

The aim of this work is to ascertain the predictability of aluminium-manganese alloy exposure time based on its as-cast weight and corrosion rate in sea water environment. The model to be derived is expected to evaluate and predict directly the exact time (exposure time) at which the Al-Mn alloy should be exposed in the sea water environment putting into consideration its as-cast weight (alloy initial weight before corrosion) and corrosion rate in such environment. The essence of this work is to determine the exact exposure time for a weighed Al-Mn alloy whose corrosion rate in the sea water environment is already known. This rules out exposure of the alloy to the corrosive environment longer than necessary; a situation that could result to very disastrous, undue corrosion penetration on the alloy and invariably, failure. The success of this work would eventually reduce abrupt failure of Al-Mn alloy in sea water environment due to over exposure.

\section{Materials and Methods}

Materials used for this work are aluminium of 96\% purity and pure granulated manganese. Details of the experimental procedure and associated process conditions are as stated in the previous report [10].

\subsection{Model Formulation}

Experimental data obtained from research work [10] were used for this work. Computational analysis of the experimental data [10] shown in Table 1, gave rise to Table 2 which indicate that:

$$
K \alpha \approx \gamma+S \beta-N_{e}
$$

Introducing the values of $K, S$ and $N_{e}$ into Equation (1) reduces it to:

$$
\begin{gathered}
0.0375 \alpha=\gamma+0.0206 \beta-0.0109 \\
\alpha=\left(\frac{\gamma+0.0206 \beta-0.0109}{0.0375}\right) \\
\alpha=26.67 \gamma+0.55 \beta-0.29
\end{gathered}
$$

where $K=0.0375$; Overall Al-Mn alloy-sea water temperature interaction factor (determined using C-NIKBRAN [11]). $S=0.0206$; First order alloy degradability

Table 1. Variation of corrosion rate with exposure time and alloy as-cast weight [10].

\begin{tabular}{ccc}
\hline$(\beta)(\mathrm{mm} / \mathrm{yr})$ & $(\alpha)(\mathrm{hrs})$ & $(\gamma)(\mathrm{g})$ \\
\hline 0.0104 & 336 & 12.0754 \\
0.0140 & 450 & 12.3911 \\
0.0157 & 504 & 12.4775 \\
0.0105 & 600 & 13.2012 \\
0.0062 & 672 & 13.7434 \\
\hline
\end{tabular}

Table 2. Variation of $0.0375 \alpha$ with $\gamma+0.0206 \beta-0.0109$.

\begin{tabular}{ccccc}
\hline $0.0375 \alpha$ & $(\gamma)$ & $0.0206 \beta$ & 0.0109 & $\gamma+0.0206 \beta-0.0109$ \\
\hline 0.00144 & 0.0104 & 0.00021 & 0.0109 & 0.00141 \\
0.00193 & 0.0140 & 0.00029 & 0.0109 & 0.00179 \\
0.00216 & 0.0157 & 0.00032 & 0.0109 & 0.00192 \\
0.00257 & 0.0105 & 0.00022 & 0.0109 & 0.00252 \\
0.00288 & 0.0062 & 0.00013 & 0.0109 & 0.00293 \\
\hline
\end{tabular}

Coefficient (determined using C-NIKBRAN [11]); $N_{e}=$ 0.0109 ; Film solubility-adhesion ratio in sea water (determined using C-NIKBRAN [11]); $(\beta)=$ Corrosion rate $(\mathrm{mm} / \mathrm{yr}) ;(\alpha)=$ Exposure time $(\mathrm{yr}) ;(\gamma)=$ Initial weight of alloy $(\mathrm{kg})$.

\subsection{Boundary and Initial Conditions}

Consider solid Al-Mn alloy exposed to sea water environment and interacting with some corrosion-induced agents. The sea water is assumed to be affected by unwanted dissolved gases. Range of exposed time considered: $0.0384-0.0767$ yrs $(336-672 \mathrm{hrs})$. Initial weight range considered: $0.0121-0.0137 \mathrm{~kg}(12.0754-13.7434 \mathrm{~g})$.

Purity of aluminium used: 96\%. Concentration of manganese addition: 4\%. Details of experiment and other process conditions are as stated in the experimental technique [10].

The boundary conditions are: aerobic environment to enhance Al-Mn alloy oxidation (since the sea water contains oxygen). At the bottom of the exposed alloy, a zero gradient for the gas scalar are assumed. The exposed alloy is stationary. The sides of the solid are taken to be symmetries.

\section{Results and Discussions}

The derived model is Equation (4). Computational analysis of Table 1 gave rise to Tables 2 and 3. The derived model is two-factorial in nature because it is a constituent of two input process factors: as-cast weight (initial alloy weight) and corrosion rate. This implies that the predicted exposure time for the Al-Mn alloy in sea water environment is dependent on just two factors: as-cast weight and corrosion rate of the alloy.

\subsection{Model Validation}

The validity of the model is strongly rooted on Equation (2) (core model equation) where both sides of the equation are correspondingly approximately equal. Table 2 also agrees with Equation (2) following the values of $0.0375 \alpha$ and $\gamma+0.0206 \beta-0.0109$ evaluated from the experimental results in Table 1. Furthermore, the derived model was validated by comparing the exposure time predicted by the model and that obtained from the experiment [10]. This was done using various analytical techniques. 
Table 3. Evaluated variation of corrosion rate of Al-Mn alloy with its as-cast weight and exposure time.

\begin{tabular}{ccc}
\hline$(\beta)(\mathrm{mm} / \mathrm{yr})$ & $(\alpha)(\mathrm{yrs})$ & $(\gamma)(\mathrm{kg})$ \\
\hline 0.0104 & 0.0384 & 0.0121 \\
0.0140 & 0.0514 & 0.0124 \\
0.0157 & 0.0575 & 0.0125 \\
0.0105 & 0.0685 & 0.0132 \\
0.0062 & 0.0767 & 0.0137 \\
\hline
\end{tabular}

\subsection{Computational Analysis}

Computational analysis of the experimental and modelpredicted exposure time was carried out to ascertain the degree of validity of the derived model. This was done by comparing the depth of corrosion penetration obtained by calculations involving experimental results, and predicted directly by the model.

The depth of corrosion penetration for Al-Mn alloy during the period of exposure in the sea water environment $C_{D}(\mathrm{~mm})$ was calculated from the equation;

$$
C_{D}=\Delta \beta \times \Delta \alpha
$$

$\Delta \beta=$ Change in the corrosion rates $\beta_{2}, \beta_{1}$ within a range of exposure time: $\alpha_{1}-\alpha_{2} . \Delta \alpha=$ Change in the alloy exposure time $\alpha_{2}, \alpha_{1}$.

Considering experimental results of points $(0.0384$, $0.0104)$ and $(0.0575,0.0157)$ for $\left(\alpha_{1}, \beta_{1}\right)$ and $\left(\alpha_{2}, \beta_{2}\right)$ respectively (during the period corrosion rate was increasing), (as in Figure 1) and substituting them into Equation (5), gives $1.0123 \times 10^{-4} \mathrm{~mm}$ as the depth of corrosion penetration on the alloy during the actual corrosion process. Also similar plot (as in Figure 2) using model-predicted results of points $(0.0384,0.0104)$ and $(0.0520,0.0157)$ for $\left(\alpha_{1}, \beta_{1}\right)$ and $\left(\alpha_{2}, \beta_{2}\right)$ respectively, during the period corrosion rate was increasing and substituting them into Equation (5) gives the depth of corrosion penetration on the alloy as $0.7208 \times 10^{-4} \mathrm{~mm}$. This is the model-predicted depth of corrosion penetration on the alloy. Furthermore, substituting experimental results of points $(0.0575,0.0157)$ and $(0.0767,0.0062)$ for $\left(\alpha_{1}, \beta_{1}\right)$ and $\left(\alpha_{2}, \beta_{2}\right)$ respectively (during the period corrosion rate was decreasing), (as in Figure 1) into Equation (5), gives $-1.8240 \times 10^{-4} \mathrm{~mm}$ as the depth of corrosion penetration on the alloy.

On other hand, substituting model-predicted results of points $(0.0520,0.0157)$ and $(0.0788,0.0062)$ for $\left(\alpha_{1}, \beta_{1}\right)$ and $\left(\alpha_{2}, \beta_{2}\right)$ respectively, during decreasing corrosion rate (as in Figure 2) into Equation (5) gives $-2.5460 \times$ $10^{-4} \mathrm{~mm}$. The negative signs preceding the magnitudes of the depth of corrosion penetration do not indicate that the depth of the penetration is negative, but that the corrosion penetration occurred when the alloy corrosion rate is decreasing and so are discarded. Based on the foregoing, the depths of corrosion penetration during the period corrosion rate was decreasing as obtained from experiments

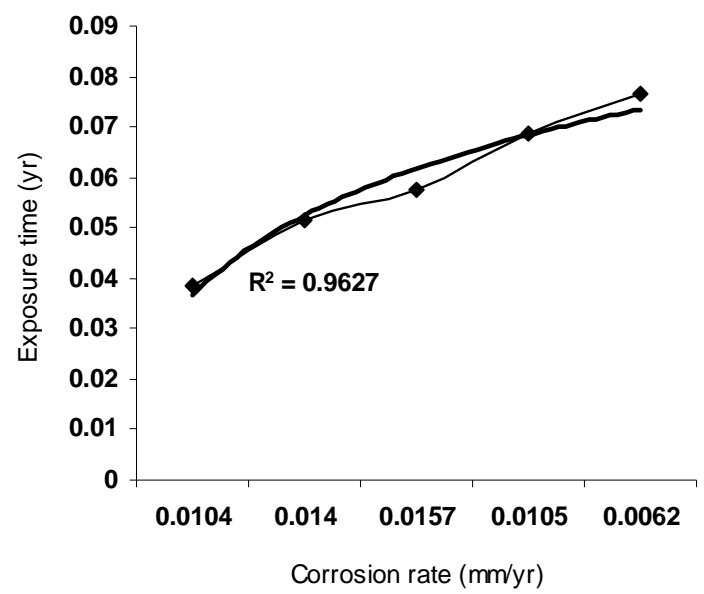

Figure 1. Coefficient of determination between alloy exposure time and its corrosion rate as obtained from the experiment [10].

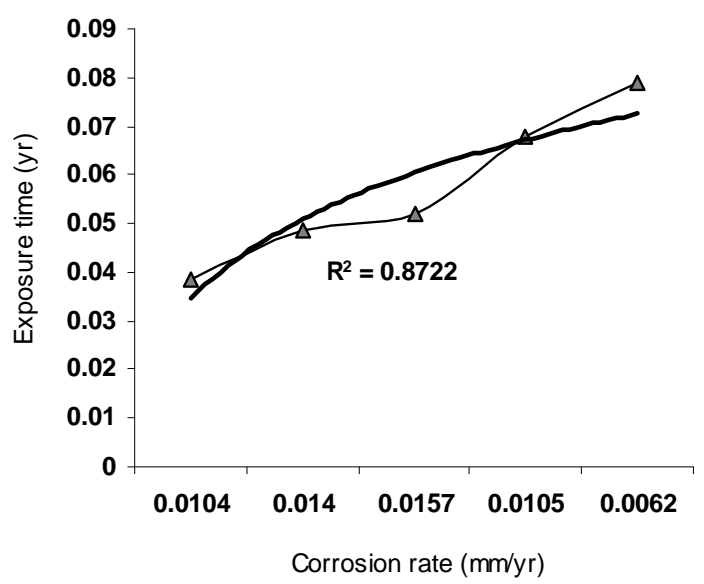

Figure 2. Coefficient of determination between alloy exposure time and its corrosion rate as predicted by derived model.

[10] and derived model are $1.8240 \times 10^{-4}$ and $2.5460 \times$ $10^{-4} \mathrm{~mm}$ respectively.

\subsection{Statistical Analysis}

Statistical analysis of model-predicted and experimentally evaluated exposure time for each value of as-cast weight and alloy corrosion rate considered shows a standard error (STEYX) of $0.0017 \% \& 0.0044 \%$ and $0.0140 \%$ $\& 0.0150 \%$ respectively. The standard error was evaluated using a Microsoft Excel [12].

Furthermore, as a way validating the derived model, regression model (highlighted from [12]) was used to predict the corresponding exposure time for the values of as-cast weight and corrosion rate considered, and the results are shown in Figures 3 and 4. On the other hand, the standard error in predicting the exposure time for each value of corrosion rate considered is $0.0119 \%$.

The correlations between exposure time and as-cast 
weight as well as exposure time and corrosion rate as obtained from derived model, regression model and experimental results [10] were calculated. This was done by considering the coefficients of determination $R^{2}$ from Figures 1-6, using the equation:

$$
R=\sqrt{R^{2}}
$$

The evaluated correlations are shown in Tables 4 and 5. The model was also validated by comparing its results of evaluated correlations between exposure time and ascast weight as well as exposure time and corrosion rate with that evaluated using experimental and regression model-predicted results. Tables 4 and $\mathbf{5}$ show that the correlation results from experiment, derived model (D$\mathrm{MoD}$ ) and R-MoD are in proximate agreement.

\subsection{Graphical Analysis}

Results predicted by the regression model were plotted;

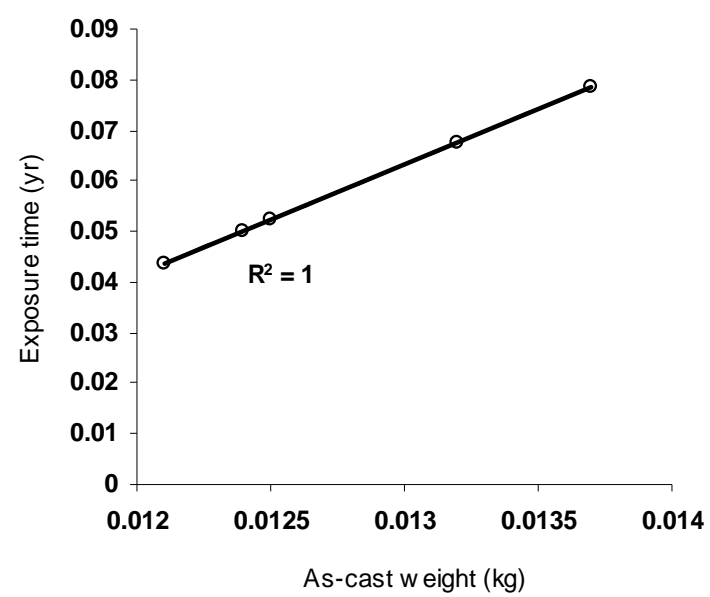

Figure 3. Coefficient of determination between alloy exposure time and its as-cast weight as predicted by regression model.

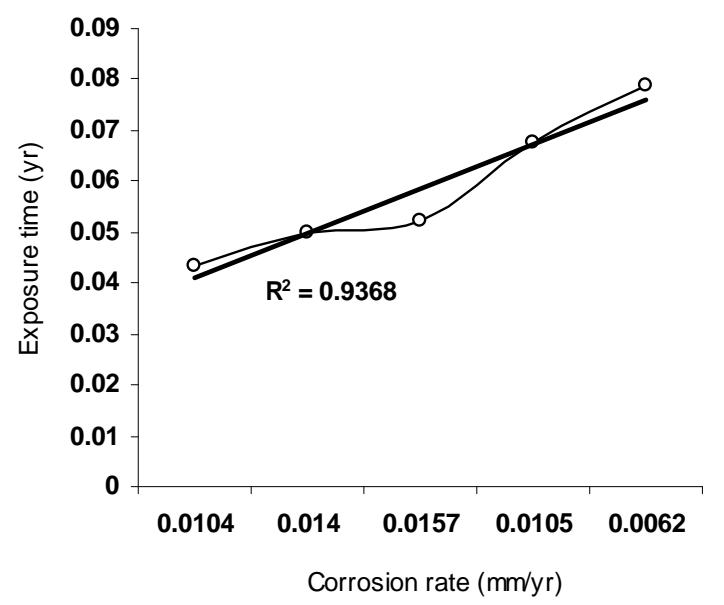

Figure 4. Coefficient of determination between alloy exposure time and its corrosion rate as predicted by regression model.

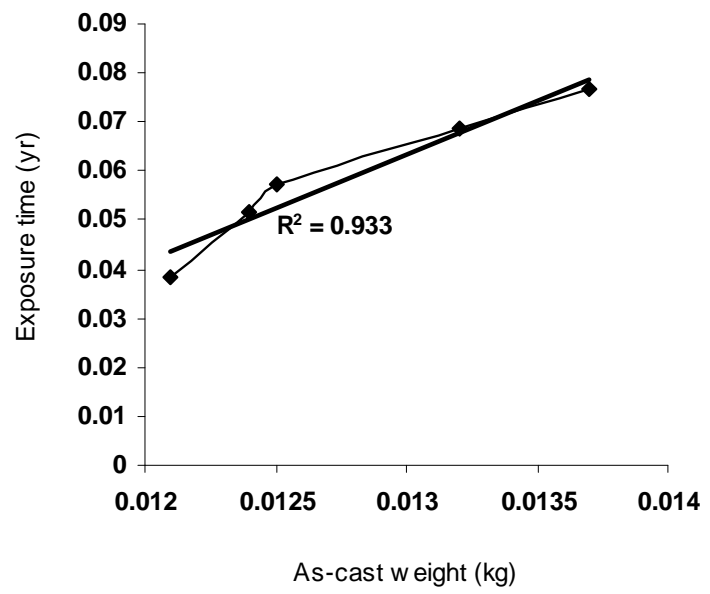

Figure 5. Coefficient of determination between alloy exposure time and its as-cast weight as obtained from the experiment [10].

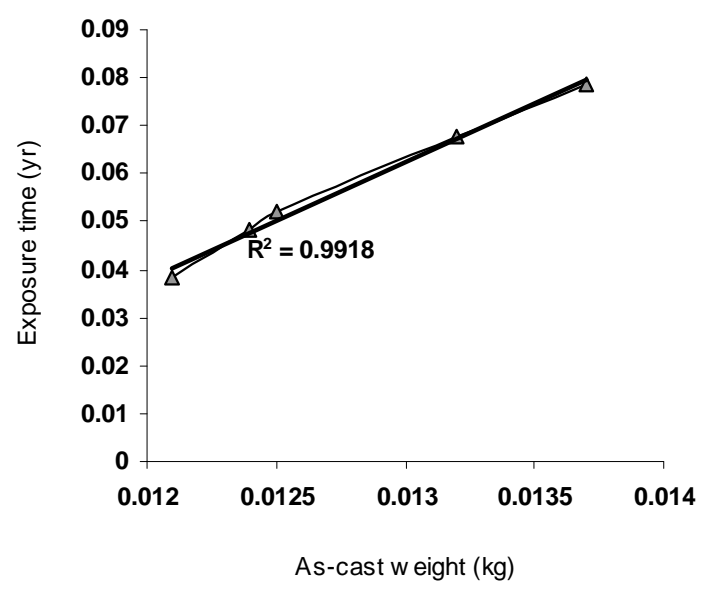

Figure 6. Coefficient of determination between alloy exposure time and its as-cast weight as predicted by derived model.

Table 4. Comparison of the correlations between exposure time and alloy as-cast weight as evaluated from experimental, derived model and regression predicted results.

\begin{tabular}{cccc}
\hline \multirow{2}{*}{ Analysis } & \multicolumn{3}{c}{ Based on alloy as-cast weight } \\
\cline { 2 - 4 } & ExD & D-MoD & R-MoD \\
\hline CORRELL & 0.9659 & 0.9659 & 1.0000 \\
\hline
\end{tabular}

Table 5. Comparison of the correlations between exposure time and alloy corrosion rate as evaluated from experimental, derived model and regression predicted results.

\begin{tabular}{cccc}
\hline \multirow{2}{*}{ Analysis } & \multicolumn{3}{c}{ Based on corrosion rate } \\
\cline { 2 - 4 } & ExD & D-MoD & R-MoD \\
\hline CORRELL & 0.9812 & 0.9339 & 0.9679 \\
\hline
\end{tabular}

exposure time against alloy as-cast weight and corrosion rate respectively along with results from the experiment and derived model to analyze its spread and trend relative to results from experiment and derived model. 
Comparative graphical analysis of Figures $\mathbf{7}$ and $\mathbf{8}$ shows very close alignment of the curves from derived model and experiment. Figures $\mathbf{9}$ and $\mathbf{1 0}$ also indicate a close alignment of curves from derived model (MoD), regression model (R-MoD) predicted results as well as experimental (ExD).

\subsection{Deviational Analysis}

Comparative analysis of exposure time from the experiment [10] and derived model revealed deviations on the part of the model-predicted values relative to values obtained from the experiment. This is attributed to the fact that the surface properties of the alloy and the physiochemical interaction between the alloy and corrosion induced agents (in the sea water) were not considered during the model formulation. This necessitated the introduction of correction factor, to bring the model-predicted corrosion rate to those of the corresponding experimental values.

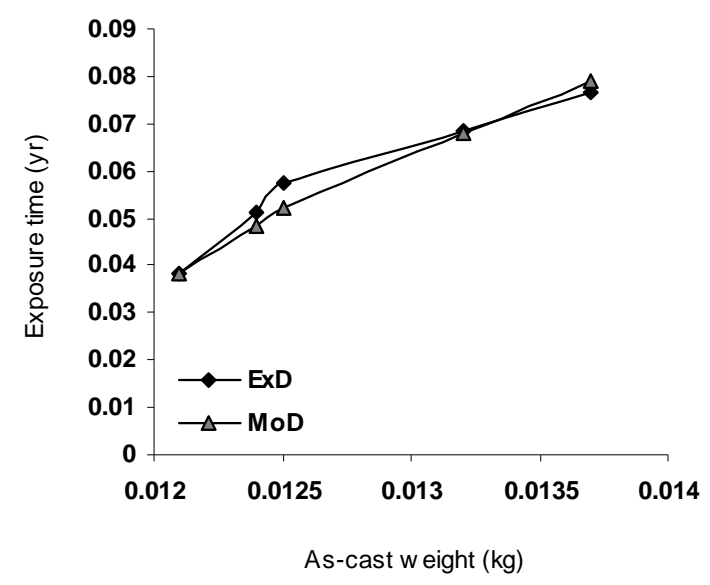

Figure 7. Comparison of the alloy exposure time (relative to its as-cast weight) as obtained from experiment [10] and derived model.

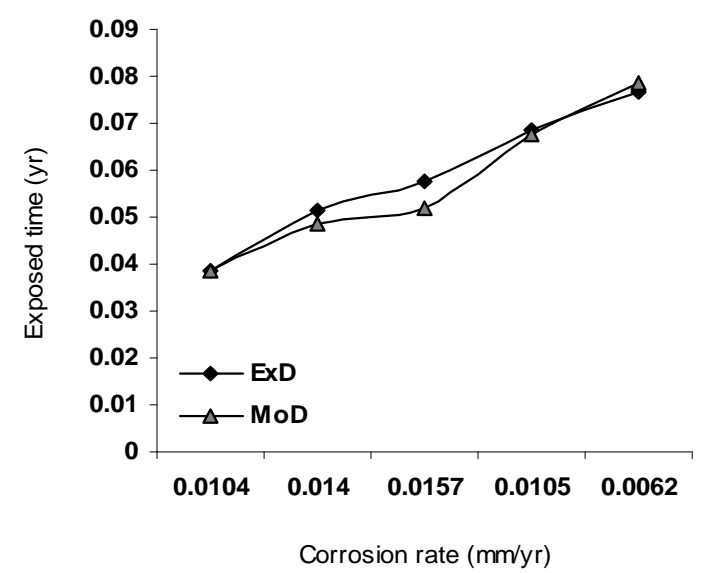

Figure 8. Comparison of the alloy exposure time (relative to its corrosion rate) as obtained from experiment [10] and derived model.

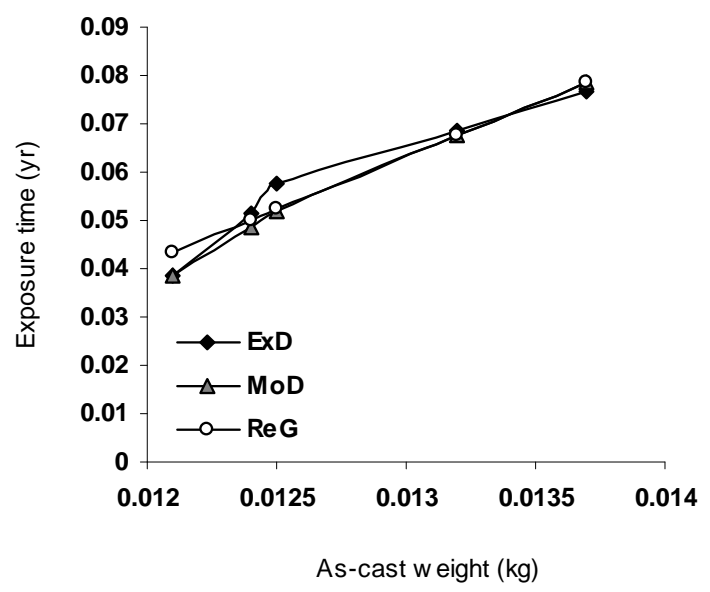

Figure 9. Comparison of the alloy exposure time (relative to its as-cast weight) as obtained from experiment [10] derived and regression model.

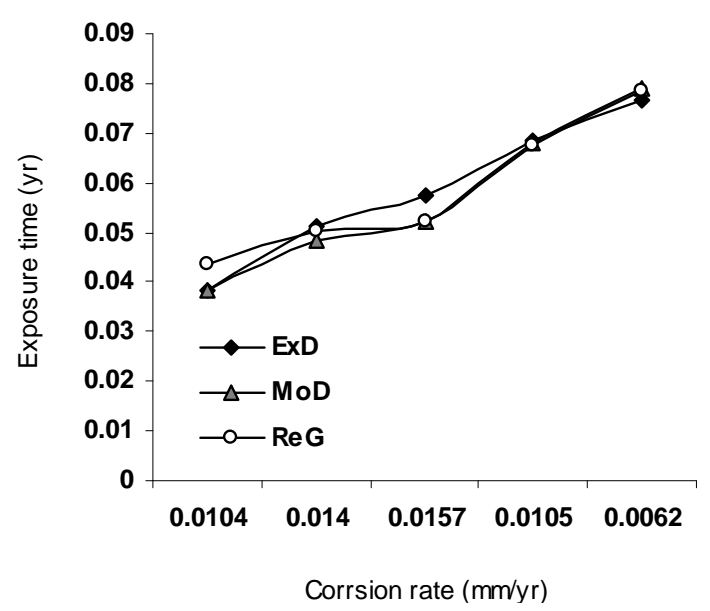

Figure 10. Comparison of the alloy exposure time (relative to its corrosion rate) as obtained from experiment [10] derived and regression model.

Deviation $(D n)$ of model-predicted corrosion rate from that of the experiment [10] is given by

$$
D n=\left(\frac{P^{C R}-E^{C R}}{E^{C R}}\right) \times 100
$$

Correction factor $(\mathrm{Cr})$ is the negative of the deviation i.e.

$$
C r=-D n
$$

therefore

$$
C r=-\left(\frac{P^{C R}-E^{C R}}{E^{C R}}\right) \times 100
$$

where: $P^{C R}=$ Model-predicted exposure time (yr); $E^{C R}=$ Exposure time obtained from experiment [10] (yr); $\mathrm{Cr}=$ Correction factor (\%); Dn = Deviation (\%).

Introduction of the corresponding values of $\mathrm{Cr}$ from Equation (9) into the model gives exactly the corre- 
sponding experimental corrosion rate.

Figures 11 and 12 show that the maximum deviation of the mode-predicted exposure time from the corresponding experimental values is less than $10 \%$ and quite within the acceptable deviation limit of experimental results. These figures show that least and highest magnitudes of deviation of the model-predicted exposure time (from the corresponding experimental values) are $0 \%$ and $-9.57 \%$ which corresponds to exposure times: 0.0384 and $0.0520 \mathrm{yr}$, alloy as-cast weight; 0.0121 and 0.0125 $\mathrm{kg}$ and alloy corrosion rates; 0.0104 and $0.0157 \mathrm{~mm} / \mathrm{yr}$ respectively.

Comparative analysis of Figures 11-14 indicates that the orientation of the curve in Figures $\mathbf{1 3}$ and $\mathbf{1 4}$ is opposite that of the deviation of model-predicted exposure time (Figures 11 and 12). This is because correction factor is the negative of the deviation as shown in Equations (8) and (19). It is believed that the correction factor takes care of the effects of the surface properties of the alloy which were not considered during the model formulation. Figures $\mathbf{1 3}$ and $\mathbf{1 4}$ indicate that the least and highest magnitudes of correction factor to the model-

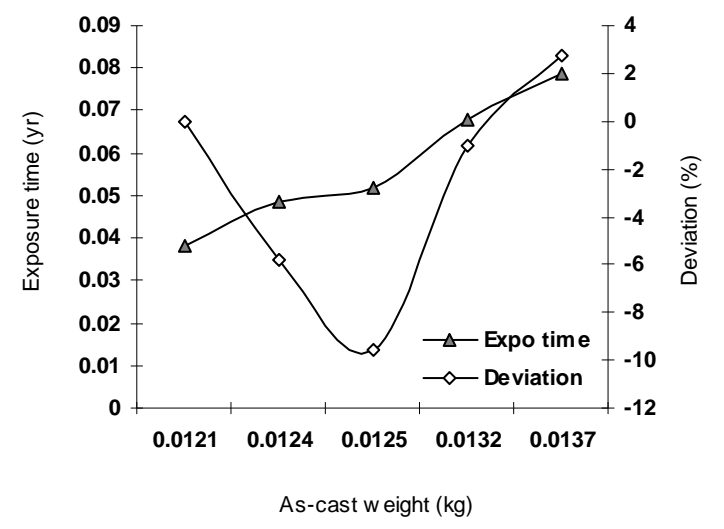

Figure 11. Variation of model-predicted alloy exposure time (relative to its as-cast weight) with its associated deviation from experimental values.

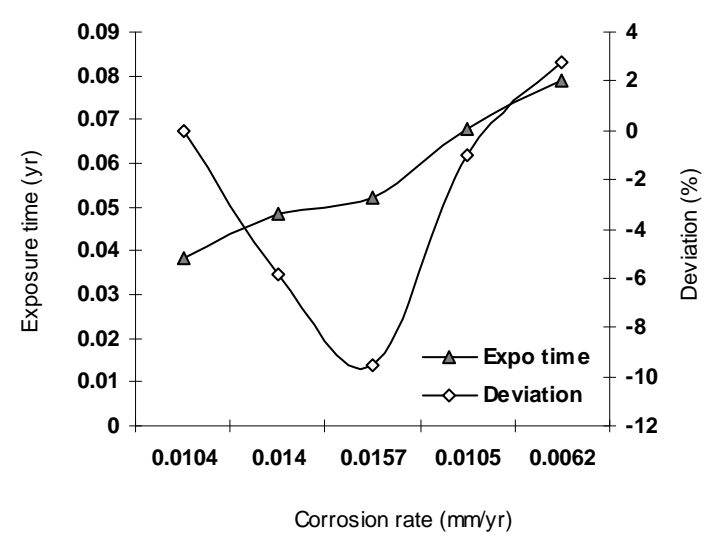

Figure 12. Variation of model-predicted alloy exposure time (relative to its corrosion rate) with its associated deviation from experimental values.

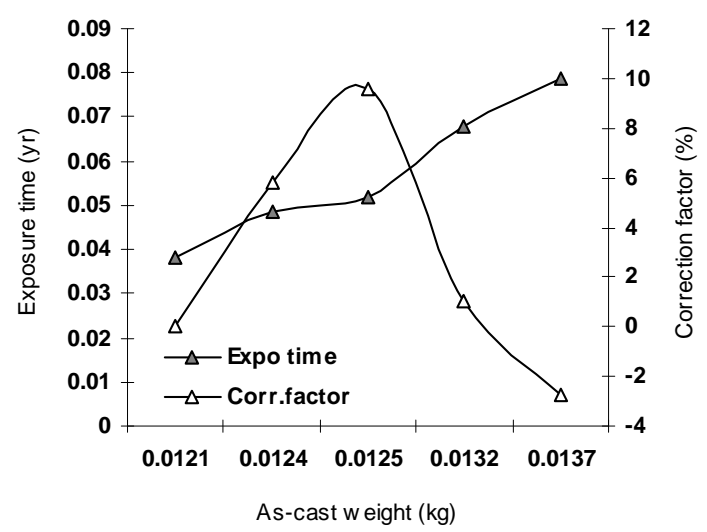

Figure 13. Variation of model-predicted alloy exposure time (relative to its as-cast weight) with its associated correction factor.

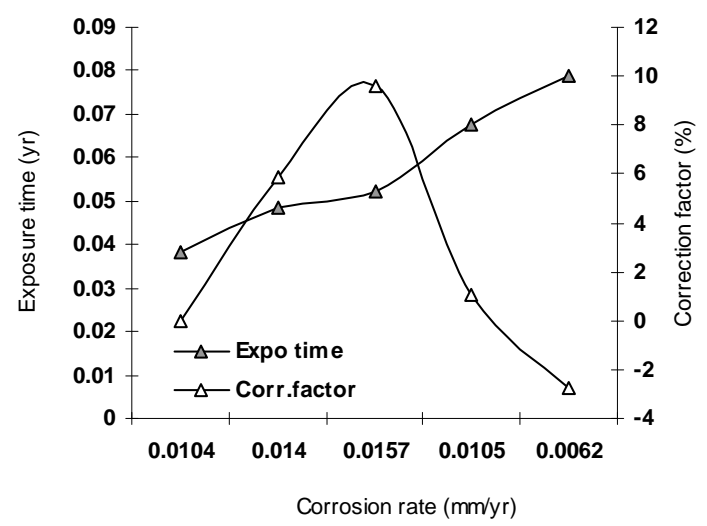

Figure 14. Variation of model-predicted alloy exposure time (relative to its corrosion rate) with its associated correction factor.

predicted exposure time are 0 and $+9.57 \%$ which corresponds to exposure times: 0.0384 and $0.0520 \mathrm{yr}$, alloy as-cast weight; 0.0121 and $0.0125 \mathrm{~kg}$ and alloy corrosion rates; 0.0104 and $0.0157 \mathrm{~mm} / \mathrm{yr}$ respectively.

It is important to state that the deviation of model predicted results from that of the experiment is just the magnitude of the value. The associated sign preceding the value signifies that the deviation is deficit (negative sign) or surplus (positive sign).

\section{Conclusion}

Aluminium-manganese alloy exposure time was evaluated and predicted based on its as-cast weight and corrosion rate in sea water environment. The validity of the derived model was rooted on the core expression: $0.0375 \alpha=\gamma+0.0206 \beta-0.0109$ where both sides of the expression are correspondingly approximately equal. Statistical analysis of model-predicted and experimentally evaluated exposure time for each value of as-cast weight and alloy corrosion rate considered shows a standard error of $0.0017 \%$ \& $0.0044 \%$ and $0.0140 \%$ \& 
$0.0150 \%$ respectively. The depths of corrosion penetration (at increasing corrosion rate: $0.0104-0.0157 \mathrm{~mm} / \mathrm{yr}$ ) as predicted by derived model and obtained from experiment are $0.7208 \times 10^{-4} \& 1.0123 \times 10^{-4} \mathrm{~mm}$ and $2.5460 \times 10^{-4} \& 1.8240 \times 10^{-4} \mathrm{~mm}$ (at decreasing corrosion rate: $0.0157-0.0062 \mathrm{~mm} / \mathrm{yr}$ ) respectively. Deviational analysis indicates that the maximum deviation of the model-predicted alloy exposure time from the corresponding experimental value is less than $10 \%$.

\section{REFERENCES}

[1] C. E. Ekuma and N. E. Idenyi, "Statistical Analysis of the Influence of Environment on Prediction of Corrosion from Its Parameters," Research Journal of Physics, Vol. 1, No. 1, 2007, pp. 27-34. http://dx.doi.org/10.3923/rip.2007.27.34

[2] M. Stratmann, K. Bohnenkamp and W. J. Engell, "An Electrochemical Study of Phase Transitions in Rust Layers," Corrosion Science, Vol. 23, 1983, pp. 969-985.

[3] S. G. Stratmann and H. Strekcel, "On the Atmospheric Corrosion of Metals Which Are Covered with Thin Electrolyte Layers II, Experimental Results," Corrosion Science, Vol. 30, No. 6-7, 1990, pp. 697-714. http://dx.doi.org/10.1016/0010-938X(90)90033-2

[4] A. Samim, and S. Zarinabadi, "An Analysis of Polyethylene Coating Corrosion in Oil and Gas Pipelines," Journal of American Science, Vol. 7, 2011, pp. 10321036.

[5] O. Ogundare, I. M. Momoh, O. J. Akinribide, A. R. Ade- tunji, J. O. Borode, S. O. O. Olusunle and O. O. Adewoye, "Comparative Study of Corrosion Sensitivity of Selected Ferrous Metals in Crude Oil," Journal of Minerals \& Materials Characterization \& Engineering, Vol. 11, 2012, pp. 559-568.

[6] S. L. Jason, I. R. Richard, J. L. Edward, U. F. Alexander and J. L. Brenda, "An Evaluation of Carbon Steel Corrosion under Stagnant Seawater Conditions," Biofouling: The Journal of Bioadhesion and Biofilm Research, Vol. 20, No. 4-5, 2004, pp. 237-247.

[7] H. Möller, E. T. Boshoff and H. Froneman, "The Corrosion Behaviour of a Low Carbon Steel in Natural and Synthetic Seawaters," The Journal of the South African Institute of Mining and Metallurgy, Vol. 106, 2006, pp. 585-592.

[8] I. J. Polmear, "Light Alloys," Edward Arnold Publishers Ltd., London, 1981.

[9] C. E. Ekuma, N. E. Idenyi and A. E. Umahi, "The Effects of Zinc Addition on the Corrosion Susceptibility of Aluminium Alloys in Various Tetraoxosulphate (vi) Acid Environments," Journal of Applied Science, Vol. 7, No. 2, 2007, pp. 237-241. http://dx.doi.org/10.3923/jas.2007.237.241

[10] N. E. Idenyi, S. P. I. Ogah and J. C. Mbazor, "Corrosion Behaviour of Al-Mn Binary Alloy Systems in Selected Environments," Journal of Metallurgical and Materials Engineering, Vol. 5, 2010, pp. 37-42.

[11] C. I. Nwoye, "C-NIKBRAN-Data Analytical Memory (Software)," 2008.

[12] Microsoft Excel, 2003 Version. 